\title{
Primary Care-Based Cardiovascular Disease Risk Management After Adverse Pregnancy Outcomes: a Narrative Review
}

\author{
Mara E. Murray Horwitz, MD, MPH' ${ }^{\mathbb{D}}$, Molly A. Fisher, $M D, M S^{2}$, Christine A. Prifti, $M D^{7}$, \\ Janet W. Rich-Edwards, SCD ${ }^{3}$, Christina D. Yarrington, $M D^{4}$, \\ Katharine O. White, MD, MPH', and Tracy A. Battaglia, MD, MPH
}

'Women's Health Unit, Section of General Internal Medicine, Evans Department of Medicine, Boston Medical Center and Boston University School of Medicine, Boston, MA, USA; 2Division of Academic Internal Medicine, Allegheny Health Network, Pittsburgh, PA, USA; ${ }^{3}$ Division of Women's Health, Department of Medicine, Brigham and Women's Hospital and Harvard Medical School, Boston, MA, USA; ${ }^{4}$ Department of Obstetrics and Gynecology, Boston Medical Center and Boston University School of Medicine, Boston, MA, USA.

Several common adverse pregnancy outcomes can reveal subclinical or latent cardiovascular disease (CVD) risk, transiently exposed through the physiologic stress of pregnancy. The year after pregnancy may be a singular opportunity to identify and initiate treatment for CVD risk, even before the onset of traditional CVD risk factors. However, clinical guidance regarding CVD risk management after adverse pregnancy outcomes is lacking. We therefore conducted a systematic review of US clinical practice guidelines and professional society recommendations to inform primary care-based CVD risk management after adverse pregnancy outcomes. We identified 13 relevant publications. While most recommendations were based on limited or weak evidence, we identified several areas of consensus. First, individuals with an adverse pregnancy outcome associated with future CVD are likely to benefit from CVD risk assessment-accompanied by education, counseling, and support for lifestyle modification-beginning within the first postpartum year. Second, among clinicians, clear and consistent

SAMPLE CASE PRESENTATION A previously healthy 40-year-old G1P0 had an uncomplicated vaginal delivery at 38 1/7 weeks gestation. The pregnancy had been complicated by preeclampsia, diagnosed by elevated blood pressures and proteinuria in the 3rd trimester, for which she was monitored and had a planned induction. Her blood pressure normalized after delivery and continued to be normal at her 1- and 6-week postpartum obstetric visits. She was advised to follow up in primary care in 1 year. At her primary care visit at 1 year postpartum, she felt well and her blood pressure was normal. She was overweight (body mass index $28.1 \mathrm{~kg} / \mathrm{m}^{2}$ ), with a weight that was still above her prepregnancy baseline but reduced since delivery. No further testing was done. Her primary care clinician recommended "annual check-ups" without further explanation. Busy with work and family, the patient did not schedule a follow-up. Over the next few years, she rarely found time for exercise and adopted a diet dominated by cereal and mac'n' cheese (her child's favorite foods). Eight years later, at 48 years of age, she had an episode of chest pain while running to catch the bus. She contacted the clinic to re-establish care. Her primary care clinician diagnosed her with obesity, hypertension, prediabetes, and hyperlipidemia and referred her for an exercise stress test to evaluate her chest pain. She was subsequently diagnosed with significant nonobstructive atherosclerosis.

Received August 6, 2021

Accepted September 8, 2021

Published online January 6, 2022 documentation about adverse pregnancy outcomes and recommended follow-up is important to coordinate care after pregnancy. In addition, patients need to be informed about their pregnancy complications and associated CVD risks, so that they can make informed health care and lifestyle decisions. Finally, in general, CVD prevention in the year after an adverse pregnancy outcome focuses on lifestyle modification, reserving pharmacotherapy for the highest-risk patients and those with traditional CVD risk factors. While postpartum lifestyle interventions show promise for reducing CVD risk after adverse pregnancy outcomes, continued research to determine the optimal content, timing, and long-term effects of such interventions is needed.

J Gen Intern Med 37(4):912-21

DOI: $10.1007 / \mathrm{s} 11606-021-07149-\mathrm{x}$

(c) Society of General Internal Medicine 2021

\section{INTRODUCTION}

Cardiovascular disease (CVD) is the leading cause of death among women. ${ }^{1}$ An increasing body of evidence indicates that several common adverse pregnancy outcomes (APOs) may be important signals of CVD risk among women. ${ }^{1-4}$ The most common such APOs are hypertensive disorders of pregnancy, gestational diabetes, and preterm delivery, each affecting $\sim 10 \%$ of pregnancies and associated with a doubling or more of 10-year CVD risk ${ }^{1-4}$ (detailed descriptions in Table $1^{3-14}$ ). Despite the connections between APOs and future CVD, only half of patients see a primary care clinician (PCC) in the year after an APO, ${ }^{15,16}$ and even fewer receive CVD risk counseling informed by their pregnancy history. ${ }^{17,18}$ Missed opportunities to respond to CVD risk after pregnancy likely contribute to sex-based disparities in CVD diagnosis, management, and outcomes. ${ }^{19}$

The year after pregnancy may be a critical time to identify and intervene on CVD risk. First, APOs portend the development of traditional CVD risk factors (e.g., hypertension, obesity, and dyslipidemia), ${ }^{2,20}$ which can 
Table 1 Definitions and Epidemiology of Selected Adverse Pregnancy Outcomes Associated with Future CVD

\begin{tabular}{|c|c|c|c|}
\hline $\begin{array}{l}\text { Adverse } \\
\text { pregnancy } \\
\text { outcomes }\end{array}$ & Diagnostic criteria & Prevalence & CVD associations ${ }^{3-4 *}$ \\
\hline $\begin{array}{l}\text { Preterm delivery } \\
\left({ }^{\text {PTD })^{\dagger}}\right.\end{array}$ & Delivery at $<37$ weeks' gestation ${ }^{10}$ & $\begin{array}{l}\text { - } 6-12 \% \text { of pregnancies worldwide }{ }^{10} \\
\text { - Higher prevalence in Black } \\
\text { populations }{ }^{12}\end{array}$ & $\begin{array}{l}\text { 1.5-2-fold increased risk of } \\
\text { composite CVD, IHD, and } \\
\text { stroke }\end{array}$ \\
\hline \multirow[t]{3}{*}{$\begin{array}{l}\text { Hypertensive } \\
\text { disorders of } \\
\text { pregnancy (HDP) }\end{array}$} & $\begin{array}{l}\text { Elevated blood pressures }(\geq 140 / \geq 90 \mathrm{~mm} \mathrm{Hg} \\
\text { on } 2 \text { occasions at least } 4 \mathrm{~h} \text { apart) during } \\
\text { pregnancy }\end{array}$ & $10 \%$ of pregnancies ${ }^{5-6}$ & \\
\hline & $\begin{array}{l}\text { - Preeclampsia: HDP with } \\
\text { thrombocytopenia, impaired liver function, } \\
\text { new renal insufficiency, pulmonary edema, } \\
\text { or new-onset cerebral, or visual disturbances } \\
\text { - Eclampsia: a severe complication of } \\
\text { preeclampsia, resulting in seizures }\end{array}$ & $\begin{array}{l}\text { - 3-7\% of pregnancies } \\
\text { - } 25 \% \text { increased prevalence between } 1987 \\
\text { and } 2004^{7} \\
\text { - Higher prevalence in Black } \\
\text { populations and among patients with } \\
\text { obesity, diabetes, preexisting } \\
\text { hypertension, advanced reproductive age, } \\
\text { and primiparity }\end{array}$ & $\begin{array}{l}\cdot 1.5-3 \text {-fold increased risk of } \\
\text { composite CVD, IHD, and } \\
\text { stroke } \\
\cdot 2-4 \text {-fold increased risk of heart } \\
\text { failure, }{ }^{13-14} \text { higher if recurrent }{ }^{3}\end{array}$ \\
\hline & $\begin{array}{l}\text { - Gestational hypertension: HDP with onset } \\
\text { after } 20 \text { weeks of gestation, not meeting } \\
\text { criteria for preeclampsialeclampsia }\end{array}$ & $\cdot 6-7 \%$ of pregnancies ${ }^{11}$ & $\begin{array}{l}\text { 1.5-2-fold increased risk of } \\
\text { composite CVD, IHD, and } \\
\text { stroke }\end{array}$ \\
\hline $\begin{array}{l}\text { Gestational diabetes } \\
\text { (GDM) }\end{array}$ & $\begin{array}{l}\text { - Diabetes with onset during pregnancy } \\
\text { - Usually detected through universal } \\
\text { screening at } 24-28 \text { weeks' gestation (or first } \\
\text { prenatal visit if high risk), then diagnosed by } \\
\text { 3-h } 100 \text {-g OGTT with } \geq 2 \text { blood glucose } \\
\text { levels above the following thresholds: } \\
\text { o Fasting: } 95 \mathrm{mg} / \mathrm{dL} \\
\text { o } 1 \mathrm{~h}: 180 \mathrm{mg} / \mathrm{dL} \\
\text { o } 2 \mathrm{~h}: 155 \mathrm{mg} / \mathrm{dL} \\
\text { o } 3 \mathrm{~h}: 140 \mathrm{mg} / \mathrm{dL}\end{array}$ & $\begin{array}{l}\text { - 5-10\% of pregnancies }{ }^{10} \\
\text { - Higher prevalence in Black, }{ }^{5,8} \text { Hispanic, } \\
\text { Native American, and Asian or Pacific } \\
\text { Islander populations }\end{array}$ & $\begin{array}{l}\text { 1.5-2-fold increased risk of } \\
\text { composite CVD and IHD; } 1.3- \\
\text { fold increased risk for stroke }\end{array}$ \\
\hline
\end{tabular}

Abbreviations: CVD, cardiovascular disease; HDP, hypertensive disorders of pregnancy; IHD, ischemic heart disease; OGTT, oral glucose tolerance test

*Based on umbrella review with average follow-up period of 7-10 years ${ }^{3}$

'Note: full term is defined as $\geq 39$ weeks' gestation

appear within the year after pregnancy ${ }^{21,22}$ and are key drivers of long-term CVD risk. ${ }^{23}$ Timely follow-up after APOs may be able to prevent, diagnose, and manage traditional CVD risk factors. Second, the US reproductive-age population has low levels of preventive health care use, with the notable exception of during pregnancy. ${ }^{24}$ Pregnancy is therefore an important potential gateway to primary care, especially for those at increased risk for future disease. Third, the year after pregnancy is a "teachable window" when patients may be more motivated than usual to pursue healthy lifestyle changes. ${ }^{25}$ Finally, postpartum CVD risk management may be beneficial for future pregnancy outcomes. ${ }^{26,27}$

PCCs are well positioned but often poorly equipped to intervene on the pathway between APOs and future CVD. ${ }^{28}$ Studies suggest that most general internists do not routinely incorporate pregnancy history into CVD risk counseling. ${ }^{18}$ In addition, practical guidance for PCCs is lacking on how to assess and manage CVD risk among individuals with recent APOs. To address these knowledge gaps, we conducted a review of clinical practice guidelines and professional society recommendations to inform primary care-based CVD risk management in the year after an APO.

\section{METHODS}

We systematically searched 3 databases (PubMed, EMBASE, and CINAHL) and 9 clinical websites (Guideline Central, American College of Obstetricians and Gynecologists [ACOG], US Preventive Services Task Force [USPSTF], American Academy of Family Physicians [AAFP], American College of Physicians [ACP], Society of General Internal Medicine [SGIM], American Diabetes Association [ADA], and the American Heart Association[AHA], and American College of Cardiology [ACC]), Google, and Google Scholar for clinical practice guidelines, society recommendations, or consensus statements ${ }^{29}$ related to postpartum care in the USA, published in 2010 through 2020 (Appendix Table 1 in the supplementary information). Two authors (MMH, and MAF or CAP) independently conducted title and abstract screening followed by full-text review for recommendations relevant to primary care during the year after an APO. We excluded postpartum care recommendations up to and including the comprehensive postpartum visit (which usually takes place around 6 weeks after delivery), when most patients are still under the care of their obstetric care clinician, unless the PCC was specifically mentioned as the responsible clinician. We also excluded recommendations specific to patients with known prepregnancy CVD risk factors (e.g., chronic 
hypertension) in order to maintain the focus of the paper on CVD risk potentially revealed by an APO. A third author (CAP or MAF) resolved discrepancies. If multiple versions of a publication were available, only the most recent version was included. If an eligible publication was identified during the review of other articles, it was also included $\left(n=4^{30-33}\right)$. Of 1084 unique results, 35 articles underwent full-text review, and 13 articles were included (Appendix Figure 1 in the supplementary information).

The included publications used various recommendation grading systems and often provided ungraded recommendations; 1 included only ungraded recommendations. ${ }^{34}$ In order to standardize and synthesize the data, we converted all recommendation grades, where available, into the USPSTF format given its relative simplicity, high prevalence of use among the included publications, and familiarity with PCCs (Appendix Table 2 in the supplementary information). USPSTF grade " $A$ " indicated services that should be offered or provided (high certainty of substantial net benefit); "B," services that should be offered or provided (high certainty of moderate benefit or moderate certainty of substantial benefit); and " $\mathrm{C}$," services that should be selectively offered or provided (at least moderate certainty of small net benefit). ${ }^{35}$

We recognize that pregnancy is possible in people of all genders. However, for the purposes of transparency, we have made minimal changes to the original language of the existing recommendations, many of which use gender-specific terms (e.g., she/her, woman/women, maternal).

\section{RESULTS}

We identified 13 US guideline or society recommendation publications with clinical guidance relevant to primary carebased CVD risk management during the year after an APO (Table 2). ${ }^{5-8,30-34,36-39}$ The AHA was the first to incorporate APOs into CVD risk management guidelines in 2011. Clinical practice recommendations regarding APOs and CVD risk accumulated at an increasing rate thereafter; two-thirds were published in 2018 or later. Many publications focused on care during pregnancy but included some postpartum recommendations; ${ }^{5,7,8,36,39}$ only 3 were specific to postpartum or interpregnancy care. ${ }^{6,34,38}$

We organized care recommendations by APO (Figure 1; see Appendix Table 3 in the supplementary information for detail). Key recommendations regarding CVD risk and supporting evidence are reviewed in the text below and synthesized into a practical guide for PCCs (Figure 2).

\section{All Parous Patients}

Four publications recommended screening all parous patients for APOs $(B)^{37}(C)^{5}$ (ungraded), ${ }^{30,32}$ ideally starting within the first year postpartum $(B)^{37}(C) .^{5}$ The publications varied in terms of APOs discussed and strength of recommendations. The strongest screening recommendation came from the AHA/ASA and applied to a history of preeclampsia/ eclampsia as revealing of stroke risk $(B),{ }^{37}$ based on numerous cohort studies and meta-analyses demonstrating significant associations of preeclampsia/eclampsia with stroke and other CVD outcomes across the lifespan.

\section{Any or Unspecified Adverse Pregnancy Outcome}

For patients with any identified APO, 2 publications recommended "comprehensive CVD risk assessment" within 3 months postpartum (ungraded; see Figures 1 and 2 for details). ${ }^{5,34}$ The recommendations for CVD risk assessment within 3 months postpartum appeared to be based on expert opinion or best practices; no specific trials or cohort studies were cited.

For postpartum CVD risk management, lifestyle-based interventions were emphasized $(C)^{5,30}$ (ungraded), ${ }^{32}$ and pharmacotherapy was reserved for patients with high CVD

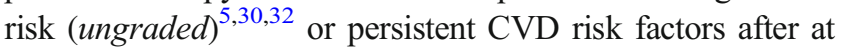
least 6 months of lifestyle modification (ungraded). ${ }^{5}$ A specific lifestyle recommendation for postpartum patients was breastfeeding $(A)^{38}$ (ungraded). ${ }^{5,39}$ Support for breastfeeding was based on multiple observational studies associating longer durations of breastfeeding with reduced risks for chronic diseases such as diabetes, ${ }^{38,39}$ hypertension, ${ }^{5,38}$ and $\mathrm{CVD}^{5}$ (specifically myocardial infarction ${ }^{38}$ ). Diet and exercise were also recommended for postpartum weight loss (ungraded), ${ }^{38,6}$ yet evidence on the most effective means of weight loss was lacking. ${ }^{38}$

Clinicians were advised to consider a history of APOs in discussions about lifestyle interventions and the potential benefits of statin therapy $(B)^{32}(C) .{ }^{33}$ A number of APOs (e.g., hypertensive disorders of pregnancy, gestational diabetes, preterm delivery, and giving birth to a small-for-gestational-age infant) were identified as "risk-enhancing factors," which may favor initiation or intensification of statin therapy among adults $40-75$ years of age with borderline risk ( 5 to $<7.5 \%$ 10 -year risk) $(C)$ or intermediate risk $(7.5$ to $<20 \% 10$-year risk) $(B)$ for atherosclerotic CVD. ${ }^{32}$ For individuals with the potential to become pregnant and taking statins (or other potential teratogens, e.g., ACE inhibitors or $\mathrm{ARBs}^{38}$ ), a "reliable form of contraception" was recommended $(C) .{ }^{32}$ Clinicians were also advised to review medications and discontinue potential teratogens prior to a subsequent pregnancy $(A){ }^{38}$

In addition, for individuals at risk of CVD, "ongoing collaborative care" between primary and obstetric care clinicians or cardiologists was suggested (ungraded). ${ }^{5}$ While lifelong CVD prevention was promoted (ungraded), ${ }^{5,34}$ shared decision-making around the relative value, costs, and convenience of ongoing CVD risk assessments was advised (ungraded), ${ }^{5,34}$ given that the optimal timing of ongoing risk assessments is unknown. ${ }^{5}$ Patient education and empowerment was also a recurrent theme (ungraded), ${ }^{5,34}$ especially in light of the fact that postpartum care is often fragmented such 


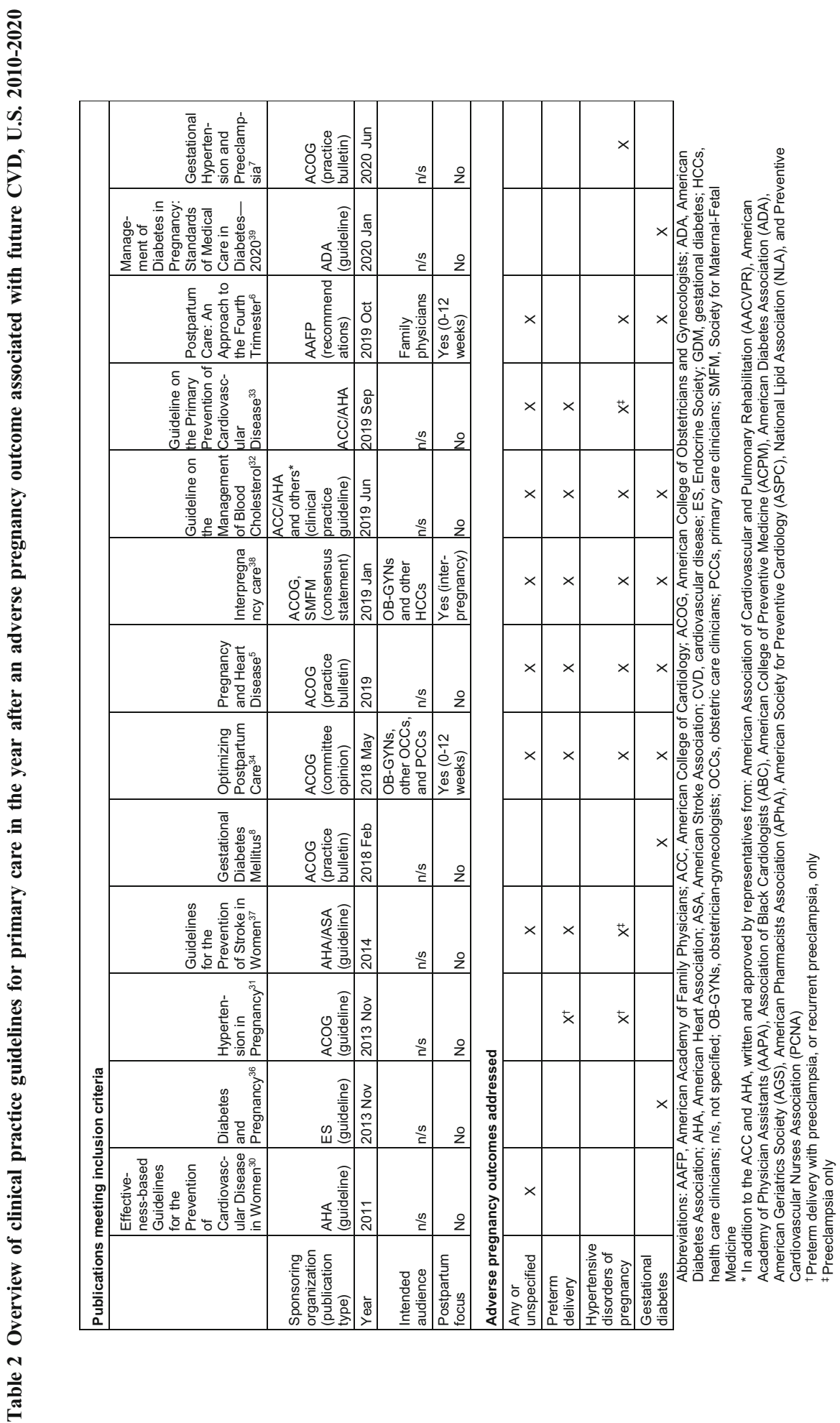


Within 1 year postpartum

$\square$ Screen for adverse pregnancy outcomes associated with future CVD history of pre-eclampsia/eclampsia $(B)^{37}(C)^{5}(U)^{30,32}$; hypertensive disorders of pregnancy $(\mathrm{C})^{5}(\mathrm{U})^{32}$; intrauterine growth restriction, idiopathic preterm delivery, placental abruption $(C)^{5}$; gestational diabetes $(C)^{5}(U)^{30,32}$; preterm delivery or giving birth to small-forgestational-age newborn $(\mathrm{U})^{30,32}$

$\square$ Document pregnancy history in the medical record $(U)^{34,38}$

$\square$ Ensure recommendations are documented in medical record, provided to patient, and communicated to care team (U)5,34

Counseling

$\square$ Encourage breastfeeding now and in future pregnancies $(A)^{38}(U)^{5,37}$ $\square$ Encourage regular aerobic activity, including among those who are lactating $(U)^{34}$

$\square$ Provide family planning counseling, including recommendations for birth spacing $>6$ months $(B)^{38}$, ideally $>18$ months $(B)^{38}$

During interpregnancy care

$\square$ Review medications and discontinue potential teratogens prior to next pregnancy $(\mathrm{A})^{38}$

$\square$ For patients with low bealth literacy, no or limited English proficiency, or other communication needs: Consider patient navigators, trained medical interpreters, health educators, and promotoras to facilitate quality care $(\mathrm{C})^{38}$

Strength and quality of recommendation indicated by USPSTF grades (A, strong; B moderate; $\mathrm{C}$, weak; and $\mathrm{U}$, ungraded). Bold text indicates recommended timefram

Abbreviations: ACE-inhibitors, angiotensin converting enzyme-inhibitors; APO, adverse pregnancy outcome; ARBs, angiotensin receptor blockers; BMI, body m index; BP, blood pressure; CVD, cardiovascular disease; FBG, fasting blood glucose; hx, history; IFG, impaired fasting glucose; IGT, impaired glucose tolerance; NSAIDs, non-steroidal anti-inflammatory drugs; OGTT, oral glucose tolerance test; PCC, primary care clinician; SGA, small for gestational age; T2DM, type 2 diabetes * Specified APOs: hypertensive disorders of pregnancy and gestational diabetes; 5,34 preterm delivery 34 intrauterine growth restriction, idiopathic preterm birth, place abruption, and excessive gestational weight gain/postpartum weight retention
$\dagger$ Class I recommendations: BP control, LDL-C-lowering therapy (goal $<100 \mathrm{mg} / \mathrm{dL}$ ), beta-blocker, ACE-inhibitor/ARB

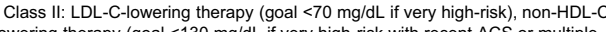
$\mathrm{g} / \mathrm{dL}$ if very high-risk with recent ACS or multiple

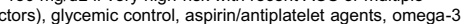

fatty acids nonpregnant thresholds $(B)^{39}$
Within 12 weeks postpartum

$\square$ Conduct comprehensive CVD risk assessment $(U)^{5,34}$, paying particular attention to the effect of social determinants of health $(\mathrm{U})^{34}$

Detailed medical hx (smoking; physical activity; breastfeeding; hx of hypertension,

diabetes, or CVD; 1st degree family hx of CVD, hypertension, or diabetes), postpartum medication monitoring, physical exam (resting BP and heart rate; BMI and waist circumference), and biochemical testing (chol/lipid profile; FBG (or OGTT if hx of gestational diabetes); urine protein assessment (Prot:Cr ratio); nutrition assessment (U)

$\square$ Counsel on identified risk factors $(\mathrm{U})^{5}$

$\square$ For low/moderate CVD risk, $(<10 \%$ 10-year risk): focus on Class I lifestyle

recommendations ${ }^{\dagger}(B)^{37}(\mathrm{U})^{5,30}$

$\square$ For bigh CVD risk, $\geq 10 \%$ 10-year risk): implement Class I lifestyle recommendations* $(B)^{37}$ and consider Class II recommendations $\ddagger(U)^{5,3}$

After 6 months to 1 year of lifestyle modification

$\square$ Repeat tests for borderline or elevated BP or lipid abnormalities; if persistently elevated, consider pharmacologic treatment $(\mathrm{U})^{5}$

$\square$ Forpatients aged $\geq 40 y$ with borderline $(5 \%$ to $<7.5 \%)$ or intermediate $(7.5 \%$ to $<20 \%) 10$-year CVD risk: Consider APO hx as a risk-enhancing factor $\left(\mathrm{U}^{33}\right.$, which may favor initiation or intensification of statin therapy for those with borderline $(C)^{32}$ or intermediate risk $(B)^{32}$ Counseling

$\square$ Counsel patients on associations between their pregnancy complication(s) and higher lifetime risk of maternal cardiometabolic disease $(U)^{5}$, especially those with high risk of CVD $(C)^{5}$

$\square$ Discuss need for annual CVD risk assessment and lifetime CVD prevention $(\mathrm{U})^{5,34}$

$\square$ Consider APO hx when discussing lifestyle interventions and the potential for benefit of statin therapy $(B)^{32}$ among other prevention interventions $(C)^{33}$

$\square$ Educate patients and engage them in shared decision-making $(U)^{5}$ with regard to their individual CVD risks $(U)^{5}$

$\square$ In family planning, incorporate patients' future pregnancy desires, personal preferences, underlying disease, and relative risks and benefits of the contraceptive option considered $(\mathrm{C})^{5}$

$\square$ For patients with bigh CVD risk: intrauterine devices are the preferred non-permanent contraceptive option $(C)^{5}$

$\square$ For patients with stroke risk factors: oral [estrogen-containing] contraceptives may be

harmful (D) ${ }^{37}$; prior to initiating oral [estrogen-containing] contraception, measure blood

pressure $(B)^{37}$ and consider aggressive therapy of stroke risk factors $(C)^{37}$; do not screen for prothrombotic mutations (D) $)^{37}$

$\square$ For patients on statins Jor other potential teratogens, e.g. ACE-inbibitors or $A B R s]$, who are sexually active and of childbearing age: counsel to use a reliable form of contraception $(C)^{32}$

PRETERM

DELIVERY

Counseling

$\square$ Counsel on higher

lifetime risk of materna

cardiometabolic disease

$(\mathrm{U})^{34}$, especially in case

of idiopathic preterm delivery

During interpregnancy

care

$\square$ Emphasize birth

spacing

recommendations of $>6$

months and ideally $>18$

months $(B)^{38}$

$\square$ Review current

recommendations to

reduce risk of recurren

preterm delivery $(\mathrm{U})^{34}$;

currently there is

insufficient evidence to

screen for or treat

asymptomatic

genitourinary infection

(B) ${ }^{38}$
Recommended visit with PCC or cardiologist at 7-10 days postpartum

During 12 weeks postpartum

$\square$ Evaluate BP for resolution of hypertension, with goal BP $<120 / 80 \mathrm{~mm}$ $\mathrm{Hg}(\mathrm{U})^{38}$

$\square$ For $B P \geq 150 / 100 \mathrm{~mm} \mathrm{Hg}$ : treat; can use oral nifedipine or labetalol (U)

$\square$ For $B P \geq 160 / 110 \mathrm{~mm} H g$ : hospitalize $(\mathrm{U})^{6}$

$\square$ For signs of end-organ damage: hospitalize $(U)^{6}$

$\square$ Continue to use NSAIDs preferentially over opioid analgesics $(A)^{7}(U)^{6}$

Within 1 year postpartum

$\square$ Document history of preeclampsia as risk factor for hypertension and stroke $(C)^{37}$

$\square$ Evaluate and treat for CVD risk factors including hypertension, obesity, smoking, and dyslipidemia $(C)^{37}$

Counseling

$\square$ Counsel that HDP is associated with higher lifetime risk of maternal cardiometabolic disease $(U)^{34}$

$\square$ Recommend lifestyle changes to manage CVD risk factors, such as achieving healthy weight $(\mathrm{U})^{6-7,38}$

$\square$ Recommend annual follow-up of BP and body weight monitoring (U) $\square$ For patients with preterm delivery: discuss suggested annual assessment of BP, FBG, and BMI; health care clinicians and patients should make this decision based on their judgment of the relative value of extra information versus expense and inconvenience $(C)^{3}$

$\square$ Convey information using proven health communication practices, such as nonmedical language, clear and slow speech, pictures, feedback $(C)^{31}$

During interpregnancy care

$\square$ Review current recommendations to reduce risk of recurrent preeclampsia, such as aspirin $(\mathrm{U})^{34}$; consider low-dose aspirin in any future pregnancy $(\mathrm{U})^{5,38}$

$\square$ For patients with early-onset preeclampsia and early preterm delivery, or recurrent preeclampsia: discuss benefits of low-dose aspirin beginning in the late first trimester to reduce incidence and morbidity of preeclampsia in future pregnancy $(\mathrm{C})^{31}$

$\square$ Avoid or discontinue ACE-inhibitors and ARBs prior to next pregnancy $(\mathrm{U})^{38}$
At 4-12 weeks postpartum

$\square$ Perform 2-hour, $75 \mathrm{~g}$ OGTT to identify diabetes, IFG levels, or IGT $(B)^{36,39}(\mathrm{C})^{6,8}(\mathrm{U})^{34,38}$; may also include a FBG $(U)^{8}$

$\square$ For normal results: rescreen every 1-3 years or more frequently between pregnancies $(C)^{8,36}(\mathrm{U})^{6,38}$ $\square$ For IFG or IGT: initiate intensive lifestyle modification or medical therapy $(A)^{39}(C)^{8}(U)^{38}$, i.e. metformin $(\mathrm{A})^{39}$; rescreen every year $(\mathrm{C})^{8}$ $\square$ For diabetes: initiate preventive or medical therapy; please note, more likely to benefit from intensive medical therapy $(C)^{8}$

During 1 year postpartum

$\square$ Monitor BP for the development of hypertension $(\mathrm{U})^{6}$

$\square$ Conduct psychosocial assessment and provide support for self-care $(C)^{39}$

Counseling

$\square$ Counsel that gestational diabetes is associated with higher lifetime risk of maternal cardiometabolic disease $(\mathrm{U})^{34}$, especially T2DM $\left(\mathrm{U}^{5}\right.$

$\square$ Counsel on the need for lifelong screening $\S$ for diabetes or prediabetes at least every 3 years $(B)^{39}$, and especially before any future pregnancies $(C)^{36}$ $\square$ Recommend lifestyle measures, such as weight loss and physical activity, to reduce risk of T2DM $(C)^{36}(\mathrm{U})^{6}$

$\square$ Recommend annual follow-up (U) ${ }^{6}$

$\square$ Note that women with diabetes or a history of gestational diabetes have the same contraceptive options and recommendations as other women $(B)^{36}(U)^{39}$

During interpregnancy care

$\square$ Recommend preconception screening for diabetes and preconception care to identify and treat hyperglycemia $(C)^{36,39}$, and early screening for gestational diabetes in the next pregnancy $(\mathrm{U})^{5}$

Figure 1 Summary of clinical practice recommendations for primary care in the year after an adverse pregnancy outcome associated with future CVD 
1

\section{ALL POSTPARTUM PATIENTS}

$\square$ Within 1 year postpartum: Screen for adverse pregnancy outcomes associated with future CVD:

$\begin{array}{ll}\text { - Placental abruption } & \text { - Hypertensive disorders of pregnancy } \\ \text { - Intrauterine growth restriction } & \text { - Gestational diabetes } \\ \text { _ Birth to SGA newborn } & \text { Preterm delivery }\end{array}$

$\square$ Document pregnancy history and care recommendations in the medical record

$\square$ Communicate recommendations to the patient and care team

\section{2 \\ ANY ADVERSE PREGNANCY OUTCOME}

$\square$ Within 1 year postpartum: Conduct CVD risk assessment, and consider the effects of social determinants of health

\begin{tabular}{|c|c|}
\hline $\begin{array}{l}\text { - Medical hx (smoking, } \\
\text { physical activity, }\end{array}$ & $\begin{array}{l}\text { Focus on lifestyle modification for } \\
\text { CVD risk factors (BP, lipids, } \\
\text { smoking) }\end{array}$ \\
\hline $\begin{array}{l}\text { breastfeeding, prior } \\
\text { diagnoses, family hx) } \\
\text { - Physical exam (BP, } \\
\text { HR, BMI, waist circ.) } \\
\text { - Labs (lipids. FBG or }\end{array}$ & $\begin{array}{l}\text { Persistently elevated BP or lipids } \\
\text { after } 6 \text { months-1 year of } \\
\text { lifestyle intervention }\end{array}$ \\
\hline $\begin{array}{l}\text { OGTT, urine protein- } \\
\text { to-creatinine ratio) } \\
\text { - Nutrition assessment }\end{array}$ & $\begin{array}{l}\text { Implement lifestyle modification, } \\
\text { and consider pharmacologic therapy } \\
\text { as needed to control CVD risk } \\
\text { factors }\end{array}$ \\
\hline
\end{tabular}

$\square$ Counsel on increased risk for CVD

$\square$ Note that APO hx may favor preventive therapy (e.g., statins)

$\square$ Engage in shared decision-making regarding plan for ongoing (e.g. annual) CVD risk assessment
3

\section{HYPERTENSIVE DISORDERS OF PREGNANCY}

$\square$ During 12 weeks postpartum: Evaluate BP for resolution of hypertension

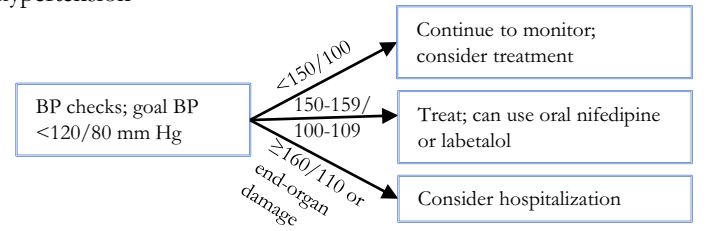

$\square$ Within 1 year postpartum: Counsel on increased risk for hypertension and CVD

$\square$ Recommend annual CVD risk assessment

\section{GESTATIONAL DIABETES}

$\square$ At 4-12 weeks postpartum: Screen for diabetes or impaired glucose tolerance
may add FBG

$\square$ Within 1 year postpartum: Conduct psychosocial assessment and provide support for self-care

$\square$ Counsel on increased risk of diabetes

$\square$ Recommend annual follow-up

\section{COUNSELING (ALL PATIENTS)}

Encourage breastfeeding $\bullet$ Encourage regular aerobic activity $\bullet$ Provide individualized, patient-centered family planning support $\bullet$ Engage in shared decision-making

During interpregnancy care: Discuss recommended interpregnancy intervals of $>6$ and ideally $>18$ months $\bullet$ Avoid or discontinue potential teratogens $\bullet$ Review recommendations to reduce risk of recurrent complications (e.g. low-dose aspirin for preeclampsia; early screening/treatment for T2DM or GDM)

Figure 2 Practical guide to primary care in the year after an adverse pregnancy outcome associated with future CVD

that postpartum patients may have to coordinate or initiate much of their care. ${ }^{5}$

\section{Hypertensive Disorders of Pregnancy}

Eight publications provided recommendations specifically for patients with a recent hypertensive disorder of pregnancy. ${ }^{5-}$ 7,31,32,34,37,38 Key recommendations included early postpartum follow-up with a PCC or cardiologist $(C)$, , and-during the first 12 weeks postpartum - close monitoring to ensure resolution of hypertension (ungraded) ${ }^{38}$ with aggressive treatment as needed for elevated blood pressures (ungraded). ${ }^{6}$

For individuals with both preeclampsia and preterm delivery, annual CVD risk assessment was suggested $(C) .{ }^{31}$ The authors of the recommendation acknowledged that because "the value and appropriate timing of assessment is not yet established," patients should be involved in shared decisionmaking regarding plans for ongoing CVD risk assessment. ${ }^{31}$

\section{Gestational Diabetes}

Seven publications provided recommendations specifically for patients with recent gestational diabetes. $5,6,8,34,36,38,39$ They consistently recommended glycemic testing using a 75-g, 2- h oral glucose tolerance test postpartum $(B)^{36,39}(C)^{6,8}$ (ungraded). ${ }^{34,38}$ The most commonly recommended timeframe

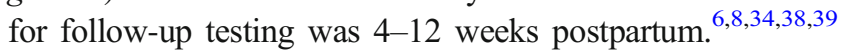
The authors of the recommendations cited consistent observations that gestational diabetes was associated with manifold increased risks of future prediabetes and diabetes. ${ }^{36,39}$

For individuals with prior gestational diabetes and normal postpartum glycemic testing, repeat testing was recommended every $1-3$ years at least $(C)^{8,36}$ (ungraded). ${ }^{6,38}$ For those with findings of impaired fasting glucose or impaired glucose tolerance, lifestyle modification or medical therapy (specifically metformin ${ }^{39}$ ) was recommended $(A)^{39}(C)^{8}$ (ungraded), ${ }^{38}$ followed by repeat testing every year $(C){ }^{8}$ The authors of the grade A recommendation ${ }^{39}$ cited a large randomized clinical trial, in which intensive lifestyle modification was as effective as metformin at preventing progression from gestational diabetes to type 2 diabetes (35-40\% lower 10-year incidence) when compared with placebo. ${ }^{40}$ Many publications recommended counseling all individuals with prior gestational diabetes on their elevated risk for diabetes (ungraded $)^{5,34}$ or need for lifelong diabetes screening $(B)^{39}(C) .^{36}$ 


\section{DISCUSSION}

In this systematic review of US clinical practice recommendations for the management of CVD risk during the year after an APO, we identified 13 relevant publications from 2010 through 2020. The AHA formally recognized APOs as indicative of CVD risk in 2011, after which we observed an increasing rate of publications addressing a growing number of APOs. Recommendations were often vague or inconsistent and based on limited evidence. We found no comprehensive guidance for general internists.

Two recent publications by the ACC/AHA state that APOs can help identify individuals at increased risk for future CVD, which can inform early preventive counseling and care. ${ }^{1,2}$ There is now a large body of observational data supporting the associations between APOs and future CVD; in general, individuals with APOs are at least twice as likely to develop CVD over their lifetimes, when compared with individuals who have had only healthy pregnancies. ${ }^{2,3}$ Unfortunately, evidence to guide primary care-based CVD risk management and follow-up after APOs is limited. To our knowledge, there have been no randomized controlled trials to evaluate the optimal content and timing of CVD risk follow-up after APOs. In addition, the long-term effects of interventions to reduce CVD risk after APOs are not well established.

Despite the current evidence gaps, we identified several actions that PCCs can take to address CVD risk in the first postpartum year. First, all parous patients should be screened for a history of APOs associated with CVD risk. Any identified APO should be documented in the medical record and communicated to the patient. Patients with an APO are likely to benefit from comprehensive CVD risk assessment and counseling on their individual risks, beginning within the first postpartum year. In general, lifestyle interventions are firstline for postpartum individuals with elevated CVD risk based on their APO history. Pharmacotherapy is reserved for those with persistent uncontrolled CVD risk factors; high CVD risk ( $\geq 10 \%$ 10-year risk); or borderline or intermediate CVD risk ( $\geq 5 \%$ 10-year risk) and aged 40 years or more. Hypertensive disorders of pregnancy and gestational diabetes warrant additional close monitoring after pregnancy for the development of hypertension and hyperglycemia, respectively. Team-based care is recommended for individuals at risk for $\mathrm{CVD}^{5}$ and has been described (including the emerging field of Cardioobstetrics $^{41}$ ) in detail elsewhere. ${ }^{4}$

Clinical trial data suggest that lifestyle interventions may produce substantial and sustained improvements in CVD risk after APOs. The evidence is strongest for diabetes prevention after gestational diabetes. For example, in a large randomized controlled trial, individuals with impaired glycemic control and overweight were randomized to intensive lifestyle intervention, metformin, or placebo; the subgroup analysis of 350 participants with prior gestational diabetes revealed that intensive lifestyle modification reduced 10-year diabetes incidence by $35 \%$ (as effective as metformin), when compared with placebo. ${ }^{40}$ A meta-analysis of 11 randomized controlled trials found a similar effect size for postpartum lifestyle interventions implemented within 3 years after gestational diabetes, with a $43 \%$ reduction in 10-year diabetes incidence. ${ }^{42}$ Emerging data suggest that even brief interventions in the year after pregnancy can have sustained effects on one's CVD risk. In a randomized controlled trial of blood pressure self-management versus usual care for 6 months after hypertensive pregnancies, the intervention group had lower blood pressures ${ }^{43}$ a difference that persisted at 3-year follow-up. ${ }^{44}$ In summary, postpartum lifestyle interventions may be able to delay or prevent the onset of CVD risk factors and improve CVD risk factor control, with protective effects extending for years after pregnancy.

The AHA's Life's Simple 7® summarizes key activities to promote cardiovascular health: (1) manage blood pressure, (2) control cholesterol, (3) reduce blood sugar, (4) get active, (5) eat better, (6) lose weight, and (7) stop smoking. ${ }^{45}$ The postpartum period presents unique opportunities to achieve these goals. For instance, weight management can focus on losing weight gained recently during pregnancy, as postpartum weight retention (usually assessed at 6 months or 1 year after delivery) is associated with higher weight gain in future pregnancies, diabetes risk, and future obesity. ${ }^{46}$ Postpartum patients can also be encouraged to continue healthy habits that they started during pregnancy, such as smoking cessation. ${ }^{47,48}$ In addition, postpartum patients may be more motivated to adopt a healthier lifestyle for family benefit, rather than for individual benefit. ${ }^{49}$ Interpregnancy CVD risk factor control (e.g., weight loss) also appears to be important for subsequent pregnancy outcomes ${ }^{50}$ and offspring health. ${ }^{51}$ Drawing connections between the patient's health and their present and future family's wellness can strengthen postpartum CVD risk counseling and management.

Data are still needed to define the optimal content and targets of postpartum CVD risk assessment and management interventions. Current recommendations focus on identifying, treating, and preventing traditional CVD risk factors (e.g., hypertension and obesity). Traditional CVD risk factors are logical targets for intervention because they occur at increased rates within a few years of complicated pregnancies, ${ }^{2,20,52,53}$ explain most of the associations between pregnancy complications and long-term CVD risk, ${ }^{23}$ and are present in $>90 \%$ of cases of premature CVD in both men and women. ${ }^{54}$ However, many pharmacologic mainstays of CVD risk reduction (e.g., statins, ACE inhibitors, and ARBs) are of limited use during the reproductive years, due to poor or lacking fetal safety data. Meanwhile, as described above, clinical trial data on postpartum lifestyle interventions to reduce CVD risk are limited but promising. Current recommendations emphasize lifestyle modification for all but the highest-risk postpartum patients. Continued research on behavioral approaches to CVD risk reduction after APOs - including the most effective means to support postpartum weight $\operatorname{loss}^{55}$ and the effects of breastfeeding on maternal cardiometabolic health ${ }^{56}$ - is essential to inform practice.

Data are also lacking on the optimal timing of postpartum CVD risk assessment and management. Current 
recommendations support CVD risk assessment, counseling, and management (as needed) beginning within the first postpartum year. ACOG suggests that the ideal timing may be within 3 months postpartum. ${ }^{5,34}$ One advantage of earlier postpartum CVD risk assessment is that it can be initiated by the obstetric care clinician (i.e., before patients transition out of pregnancybased care and may be lost to follow-up). However, many CVD risk markers appear to be elevated for several months after pregnancy, especially among individuals with recent APOs. ${ }^{57}$ Early postpartum CVD risk assessment may exaggerate longterm CVD risk. It may therefore be reasonable to consider postponing CVD risk assessment (with the exception of glycemic testing after gestational diabetes) until 3-6 months postpartum. ${ }^{28}$ Ongoing CVD risk assessments are likely to be beneficial, as absolute CVD risk increases with age.

Unfortunately, recommendations for CVD risk management after APOs are often unmet in primary care. Only about half of patients with medically complicated pregnancies see a PCC during the postpartum year, ${ }^{15,16}$ and their PCC (in particular if they are an internist) is unlikely to identify and incorporate pregnancy history into CVD risk assessment. ${ }^{17,18}$ In addition, follow-up after APOs is unequal across society. Hypertensive disorders of pregnancy are less likely to be followed by a primary care visit among Black or Hispanic versus White patients, ${ }^{15}$ and are twice as likely to result in a hypertensive postpartum readmission among Black versus White patients. ${ }^{58}$ Postpartum incident CVD is 3 times as common among individuals with public versus commercial insurance. ${ }^{59}$ Barriers to postpartum follow-up occur at many levels of the health care system, including: insurance discontinuities after pregnancy that disproportionately affect lowincome people and people of color; ${ }^{60}$ poor care coordination due to inconsistent documentation, haphazard handovers, and confusion about who is responsible for care $;^{61}$ among PCCs, inadequate training in gender-specific CVD risk assessment ${ }^{62}$ and pregnancy-related health topics; ${ }^{63}$ among patients, ineffective communication from their clinicians and low levels of knowledge regarding their APO-associated health risks; ${ }^{49,61}$ and competing priorities for patients (e.g., newborn care, returning to work) as well as clinicians. ${ }^{61}$

Improving PCC practice is not enough to ensure optimal postpartum care; infrastructure and policy change are also required. ${ }^{64,65}$ First and foremost, universal health insurance for the entire year after pregnancy is essential. ${ }^{60}$ Comparisons between Medicaid expansion and non-expansion states suggest that extending the duration of postpartum health insurance leads to increased outpatient follow-up, especially after medically complicated pregnancies. ${ }^{66}$ In addition, specialized postpartum transition clinics have been associated with improved postpartum transitions to primary care ${ }^{67,68}$ and blood pressure management. ${ }^{68}$ Postpartum patient navigation shows promise as another means to support continuity of care after pregnancy. ${ }^{69} \mathrm{Clin}$ ical support tools embedded in the electronic medical record (e.g., obstetric event flags or best practice advisories) can be used to transfer knowledge and recommendations between clinicians. Web- or app-based adjuncts to in-person care may support lifestyle change after APOs, ${ }^{70}$ by increasing patients' CVD risk knowledge and self-efficacy. ${ }^{71}$ Virtual visits and remote blood pressure monitoring have expanded during the COVID-19 pandemic and may prove beneficial for postpartum CVD risk monitoring and management, ${ }^{44,72}$ given the considerable logistical barriers to in-person visit attendance during the postpartum period. Finally, online resources including patient handouts, such as those developed by the ACC (https://www. cardiosmart.org/assets/infographic/heart-health-after-pregnancy), and a postpartum health record, such as that developed by the founders of the Maternal Health Clinic in Kingston, Can$\mathrm{ada}^{73}$ (https://www.themothersprogram.ca/sites/themothersprogram.ca/files/Postpartum\%20Health\%20Record_20AUG2019. pdf), may assist patients and their PCCs discuss and manage CVD risk after pregnancy.

\section{CONCLUSION}

Preventingpregnancy-related deaths, health inequities, and the long-term sequelae of pregnancy complications is a public health priority ${ }^{74}$ effective management of CVD risk after APOs is critical to these efforts. Clinical practice recommendations for primary care during the year after an APO are few, non-comprehensive, and limited by critical evidence gaps. However, they consistently emphasize the need for timely risk assessment, patient education and empowerment, and lifestyle modification to prevent CVD. PCCs caring for patients during the year after pregnancy must be able to (1) identify APOs associated with future CVD; (2) empower patients with information about their individual CVD risks and follow-up needs, informed by their reproductive history; and (3) support healthy behavior changes within the postpartum context. Further research is needed to clarify the optimal content, timing, and long-term health effects of postpartum interventions and follow-up to reduce CVD risk after APOs, both in the first postpartum year and beyond.

Corresponding Author: Mara E. Murray Horwitz, MD, MPH; Women's Health Unit, Section of General Internal Medicine, Evans Department of Medicine, Boston Medical Center and Boston University School of Medicine, Boston, MA, USA (e-mail: Mara. MurrayHorwitz@bmc.org).

Supplementary Information The online version contains supplementary material available at https://doi.org/10.1007/s11606-02107149-x

\section{REFERENCES}

1. Cho L, Davis M, Elgendy I, et al. Summary of Updated Recommendations for Primary Prevention of Cardiovascular Disease in Women. Journal of the American College of Cardiology. 2020;75(20):2602-2618. doi:https://doi.org/10.1016/j.jacc.2020.03.060 
2. Parikh NI, Gonzalez JM, Anderson CAM, et al. Adverse Pregnancy Outcomes and Cardiovascular Disease Risk: Unique Opportunities for Cardiovascular Disease Prevention in Women: A Scientific Statement From the American Heart Association. Circulation. Published online March 29, 2021. doi:https://doi.org/10.1161/CIR.0000000000000961

3. Okoth K, Chandan JS, Marshall T, et al. Association between the reproductive health of young women and cardiovascular disease in later life: umbrella review. BMJ. Published online October 2020:m3502. doi:https://doi.org/10.1136/bmj.m3502

4. Davis MB, Arendt K, Bello NA, et al.Team-Based Care of Women With Cardiovascular Disease From Pre-Conception Through Pregnancy and Postpartum. Journal of the American College of Cardiology. 2021;77(14):1763-1777. doi:https://doi.org/10.1016/j.jacc.2021.02.033

5. American College of Obstetricians and Gynecologists. ACOG Practice Bulletin No. 212: Pregnancy and Heart Disease. Obstetrics \& Gynecology. 2019; 133(5):e320. https://doi.org/10.1097/AOG.0000000000003243

6. Paladine HL, Blenning CE, Strangas Y. Postpartum Care: An Approach to the Fourth Trimester. AFP. 2019;100(8):485-491.

7. American College of Obstetricians and Gynecologists. ACOG Practice Bulletin No. 202: Gestational Hypertension and Preeclampsia. Obstetrics \& Gynecology. 2019;133(1):e1. https://doi.org/10.1097/AOG. 0000000000003018

8. American College of Obstetricians and Gynecologists. ACOG Practice Bulletin No. 190: Gestational Diabetes Mellitus. Obstetrics \& Gynecology. 2018;131(2):e49-e64. doi:https://doi.org/10.1097/AOG. 0000000000002501

9. Mosca L, Benjamin EJ, Berra K, et al.Effectiveness-Based Guidelines for the Prevention of Cardiovascular Disease in Women-2011 Update: A Guideline From the American Heart Association. Journal of the American College of Cardiology. 2011;57(12):1404-1423. doi:https://doi.org/10. 1016/j.jacc.2011.02.005

10. Brown HL, Smith GN. Pregnancy Complications, Cardiovascular Risk Factors, and Future Heart Disease. Obstetrics and Gynecology Clinics of North America. 2020;47(3):487-495. doi:https://doi.org/10.1016/j.ogc. 2020.04.009

11. Ying Wendy, Catov Janet M., Ouyang Pamela. Hypertensive Disorders of Pregnancy and Future Maternal Cardiovascular Risk. Journal of the American Heart Association. 2018;7(17):e009382. doi:10.1161/ JAHA.118.009382

12. Products - Data Briefs - Number 387 - October 2020. Published October 8, 2020. Accessed July 16, 2021. https://www.cdc.gov/nchs/products/ databriefs/db387.htm

13. Honigberg MC, Riise HKR, Daltveit AK, et al. Heart Failure in Women With Hypertensive Disorders of Pregnancy: Insights From the Cardiovascular Disease in Norway Project. Hypertension. 2020;76(5):1506-1513. doi:https://doi.org/10.1161/HYPERTENSIONAHA.120.15654

14. Garovic VD, White WM, Vaughan $\mathbf{L}$, et al. Incidence and Long-Term Outcomes of Hypertensive Disorders of Pregnancy. Journal of the American College of Cardiology. 2020;75(18):2323-2334. doi:https://doi. org/10.1016/j.jacc.2020.03.028

15. Lewey Jennifer, Levine Lisa D., Yang Lin, Triebwasser Jourdan E., Groeneveld Peter W. Patterns of Postpartum Ambulatory Care Follow-up Care Among Women With Hypertensive Disorders of Pregnancy. Journal of the American Heart Association. 2020;9(17):e016357. https://doi.org/ 10.1161/JAHA. 120.016357

16. Walker LO, Murphey CL, Nichols F. The Broken Thread of Health Promotion and Disease Prevention for Women During the Postpartum Period. J Perinat Educ. 2015;24(2):81-92. doi:https://doi.org/10.1891/ 1058-1243.24.2.81

17. Wilkins-Haug L, Celi A, Thomas A, Frolkis J, Seely EW. Recognition by Women's Health Care Providers of Long-Term Cardiovascular Disease Risk After Preeclampsia. Obstetrics \& Gynecology. 2015;125(6):12871292. doi:https://doi.org/10.1097/AOG.0000000000000856

18. Roth H, LeMarquand G, Henry A, Homer C. Assessing Knowledge Gaps of Women and Healthcare Providers Concerning Cardiovascular Risk After Hypertensive Disorders of Pregnancy-A Scoping Review. Front Cardiovasc Med. 2019;6. https://doi.org/10.3389/fcvm.2019.00178

19. Garcia M, Mulvagh SL, Merz CNB, Buring JE, Manson JE. Cardiovascular Disease in Women: Clinical Perspectives. Circ Res. 2016;118(8): 1273-1293. doi:https://doi.org/10.1161/CIRCRESAHA. 116.307547

20. Catov JM, McNeil RB, Marsh DJ, et al. Early Pregnancy Atherogenic Profile in a First Pregnancy and Hypertension Risk 2 to 7 Years After Delivery. J Am Heart Assoc. 2021;10(5). doi:10.1161/JAHA.120.017216

21. Benschop Laura, Duvekot Johannes J., Versmissen Jorie, van Broekhoven Valeska, Steegers Eric A.P., Roeters van Lennep Jeanine
E. Blood Pressure Profile 1 Year After Severe Preeclampsia. Hypertension. 2018;71(3):491-498. doi:https://doi.org/10.1161/HYPERTENSIONAHA. 117.10338

22. Benschop L, Duvekot JJ, Lennep JER van. Future risk of cardiovascular disease risk factors and events in women after a hypertensive disorder of pregnancy. Heart. 2019;105(16):1273-1278. doi:https://doi. org/10.1136/heartjnl-2018-313453

23. Haug EB, Horn J, Markovitz AR, et al. Association of Conventional Cardiovascular Risk Factors With Cardiovascular Disease After Hypertensive Disorders of Pregnancy: Analysis of the Nord-Trøndelag Health Study. JAMA Cardiol. 2019;4(7):628. doi:https://doi.org/10.1001/jamacardio.2019.1746

24. Pazol K, Robbins CL, Black LI, et al. Receipt of Selected Preventive Health Services for Women and Men of Reproductive Age - United States, 2011-2013. MMWR Surveill Summ. 2017;66(20):1-31. https://doi.org/ $10.15585 /$ mmwr.ss6620al

25. Seely EW, Celi AC, Chausmer J, et al. Cardiovascular Health After Preeclampsia: Patient and Provider Perspective. Journal of Women's Health. Published online September 28, 2020. https://doi.org/10. 1089/jwh.2020.8384

26. Rohlfing AB, Nah G, Ryckman KK, et al. Maternal cardiovascular disease risk factors as predictors of preterm birth in California: a casecontrol study. BMJ Open. 2020;10(6):e034145. doi:https://doi.org/10. 1136/bmjopen-2019-034145

27. Smith GN, Pudwell J, Roddy M. The Maternal Health Clinic: A New Window of Opportunity for Early Heart Disease Risk Screening and Intervention for Women with Pregnancy Complications. Journal of Obstetrics and Gynaecology Canada. 2013;35(9):831-839. doi:https:// doi.org/10.1016/S1701-2163(15)30841-0

28. Park K, Minissian MB, Wei J, Saade GR, Smith GN. Contemporary clinical updates on the prevention of future cardiovascular disease in women who experience adverse pregnancy outcomes. Clinical Cardiology. 2020;43(6):553-559. doi:https://doi.org/10.1002/clc.23374

29. Hooper A. LibGuides: Search Filters for Various Databases: PubMed. Accessed January 6, 2021. https://libguides.sph.uth.tmc.edu/search_ filters/pubmed_filters

30. Mosca L, Benjamin EJ, Berra $\mathbf{K}$, et al. Effectiveness-Based Guidelines for the Prevention of Cardiovascular Disease in Women-2011 Update: A Guideline From the American Heart Association. Journal of the American College of Cardiology. 2011;57(12):1404-1423. doi:https://doi.org/10. 1016/j.jacc.2011.02.005

31. American College of Obstetricians and Gynecologists. Hypertension in Pregnancy. American College of Obstetricians and Gynecologists; 2013.

32. Grundy SM, Stone NJ, Bailey AL, et al. 2018 AHA/ACC/AACVPR/ AAPA/ABC/ACPM/ADA/AGS/APhA/ASPC/NLA/PCNA Guideline on the Management of Blood Cholesterol: A Report of the American College of Cardiology/American Heart Association Task Force on Clinical Practice Guidelines. Circulation. 2019;139(25). https://doi.org/10.1161/CIR. 0000000000000625

33. Arnett DK, Blumenthal RS, Albert MA, et al. 2019 ACC/AHA Guideline on the Primary Prevention of Cardiovascular Disease: A Report of the American College of Cardiology/American Heart Association Task Force on Clinical Practice Guidelines. Circulation. 2019;140(11). doi:https:// doi.org/10.1161/CIR.0000000000000678

34. American College of Obstetricians and Gynecologists. Optimizing Postpartum Care. Committee Opinion No. 736. Obstetrics and Gynecology. 2018;131(5):e140-e150.

35. Grade Definitions | United States Preventive Services Taskforce. Accessed March 9, 2021. https://uspreventiveservicestaskforce.org/uspstf/aboutuspstf/methods-and-processes/grade-definitions

36. Blumer I, Hadar E, Hadden DR, et al. Diabetes and Pregnancy: An Endocrine Society Clinical Practice Guideline. J Clin Endocrinol Metab. 2013;98(11):4227-4249. doi:https://doi.org/10.1210/jc.2013-2465

37. Bushnell C, McCullough LD, Awad IA, et al. Guidelines for the Prevention of Stroke in Women: A Statement for Healthcare Professionals From the American Heart Association/American Stroke Association. Stroke. 2014;45(5):1545-1588. doi:https://doi.org/10.1161/01.str. 0000442009.06663.48

38. American College of Obstetricians and Gynecologists, Society for Maternal-Fetal Medicine. Obstetric Care Consensus No. 8: Interpregnancy Care. Obstet Gynecol. 2019;133(1):e51-72. doi:https://doi.org/10. 1097/AOG.0000000000003025

39. American Diabetes Association. 14. Management of Diabetes in Pregnancy: Standards of Medical Care in Diabetes-2020. Diabetes Care. 2020;43(Supplement 1):S183-S192. https://doi.org/10.2337/dc20S014 
40. Aroda VR, Christophi CA, Edelstein SL, et al. The Effect of Lifestyle Intervention and Metformin on Preventing or Delaying Diabetes Among Women With and Without Gestational Diabetes: The Diabetes Prevention Program Outcomes Study 10-Year Follow-Up. J Clin Endocrinol Metab. 2015;100(4): 1646-1653. doi:https://doi.org/10.1210/jc.2014-3761

41. Sharma G., Lindley K., Grodzinsky A. Cardio-Obstetrics: Developing a Niche in Maternal Cardiovascular Health. J Am Coll Cardiol. 2020;75(11):1355-1359. doi:https://doi.org/10.1016/j.jacc.2020.02. 019

42. Li N, Yang Y, Cui D, et al. Effects of lifestyle intervention on long-term risk of diabetes in women with prior gestational diabetes: A systematic review and meta-analysis of randomized controlled trials. Obesity Reviews. 2021;22(1):e13122. doi:https://doi.org/10.1111/obr.13122

43. Cairns AE, Tucker KL, Leeson P, et al.Self-Management of Postnatal Hypertension: The SNAP-HT Trial. Hypertension. 2018;72(2):425-432. doi:https://doi.org/10.1161/HYPERTENSIONAHA.118.10911

44. Kitt JA, Fox RL, Cairns AE, et al.Short-Term Postpartum Blood Pressure Self-Management and Long-Term Blood Pressure Control: A Randomized Controlled Trial. Hypertension. 0(0):HYPERTENSIONAHA. 120.17101. doi:10.1161/HYPERTENSIONAHA. 120.17101

45. My Life Check | Life's Simple 7. www.heart.org. Accessed February 11, 2021. https://www.heart.org/en/healthy-living/healthy-lifestyle/mylife-check $\% 2 \mathrm{D} \% 2$ Dlifes-simple-7

46. Sawangkum P, Louis JM. Gestational Weight Gain: Achieving a Healthier Weight Between Pregnancies. Obstetrics and Gynecology Clinics of North America. 2020;47(3):397-407. doi:https://doi.org/10.1016/j.ogc.2020. 04.003

47. Meernik C, Goldstein AO. A critical review of smoking, cessation, relapse and emerging research in pregnancy and post-partum. British Medical Bulletin. 2015;114(1):135-146. doi:https://doi.org/10.1093/bmb/ ldv016

48. Secker-Walker RH, Solomon LJ, Flynn BS, Skelly JM, Mead PB. Smoking relapse prevention during pregnancy: A trial of coordinated advice from physicians and individual counseling. American Journal of Preventive Medicine. 1998;15(1):25-31. doi:https://doi.org/10.1016/ S0749-3797(98)00029-4

49. Seely EW, Rich-Edwards J, Lui J, et al. Risk of future cardiovascular disease in women with prior preeclampsia: a focus group study. BMC Pregnancy Childbirth. 2013;13:240. doi:https://doi.org/10.1186/14712393-13-240

50. Tabet M, Banna S, Luong L, Kirby R, Chang JJ. Pregnancy Outcomes after Preeclampsia: The Effects of Interpregnancy Weight Change. Am J Perinatol. Published online June 10, 2020. doi:https://doi.org/10.1055/ s-0040-1713000

51. Taylor EJ, Wilding S, Ziauddeen N, Godfrey KM, Berrington A, Alwan NA. Change in modifiable maternal characteristics and behaviours between consecutive pregnancies and offspring adiposity: A systematic review. Obes Rev. 2020;21(11):e13048. doi:https://doi.org/10.1111/obr. 13048

52. Groenhof T. Katrien J., Zoet Gerbrand A., Franx Arie, et al. Trajectory of Cardiovascular Risk Factors After Hypertensive Disorders of Pregnancy. Hypertension. 2019;73(1):171-178. doi:https://doi.org/10.1161/ HYPERTENSIONAHA.118.11726

53. Hromadnikova I, Kotlabova K, Dvorakova L, Krofta L. Maternal Cardiovascular Risk Assessment 3-to-11 Years Postpartum in Relation to Previous Occurrence of Pregnancy-Related Complications. Journal of Clinical Medicine. 2019;8(4):544. doi:https://doi.org/10.3390/ jcm8040544

54. Khot UN. Prevalence of Conventional Risk Factors in Patients With Coronary Heart Disease. JAMA. 2003;290(7):898. doi:https://doi.org/10. 1001/jama.290.7.898

55. Christiansen PK, Skjøth MM, Rothmann MJ, Vinter CA, Lamont RF, Draborg E. Lifestyle interventions to maternal weight loss after birth: a systematic review. Systematic Reviews. 2019;8(1):327. doi:https://doi. org/10.1186/s13643-019-1186-2

56. Tørris C, Bjørnnes AK. Duration of Lactation and Maternal Risk of Metabolic Syndrome: A Systematic Review and Meta-Analysis. Nutrients. 2020;12(9):2718. doi:https://doi.org/10.3390/nu 12092718

57. Parikh NI, Laria B, Nah G, et al. Cardiovascular Disease-Related Pregnancy Complications Are Associated with Increased Maternal Levels and Trajectories of Cardiovascular Disease Biomarkers During and After Pregnancy. Journal of Women's Health. 2020;29(10):1283-1291. doi:https://doi.org/10.1089/jwh.2018.7560
58. Chornock R, Iqbal SN, Kawakita T. Racial Disparity in Postpartum Readmission due to Hypertension among Women with PregnancyAssociated Hypertension. Am J Perinatol. Published online June 2020. doi:https://doi.org/10.1055/s-0040-1712530

59. Syeda SK, Wen T, Wright JD, Goffman D, D'Alton ME, Friedman AM Postpartum cardiac readmissions among women without a cardiac diagnosis at delivery. The Journal of Maternal-Fetal \& Neonatal Medicine. 2020;0(0):1-7. doi:https://doi.org/10.1080/14767058.2020.1863368

60. Kumar NR, Borders A, Simon MA. Postpartum Medicaid Extension to Address Racial Inequity in Maternal Mortality. Am $J$ Public Health 2021;111(2):202-204. doi:https://doi.org/10.2105/AJPH.2020.306060

61. McCloskey L, Sherman ML, St John M, et al. Navigating a "Perfect Storm" on the Path to Prevention of Type 2 Diabetes Mellitus After Gestational Diabetes: Lessons from Patient and Provider Narratives. Matern Child Health J. 2019;23(5):603-612. doi:https://doi.org/10. 1007/s10995-018-2649-0

62. Bairey Merz CN, Andersen H, Sprague E, et al. Knowledge, Attitudes, and Beliefs Regarding Cardiovascular Disease in Women: The Women's Heart Alliance. Journal of the American College of Cardiology. 2017;70(2):123-132. doi:https://doi.org/10.1016/j.jacc.2017.05.024

63. Casas RS, Hallett LD, Rich CA, Gerber MR, Battaglia TA. Program Directors' Perceptions of Resident Education in Women's Health: A National Survey. Journal of Women's Health. 2016;26(2):133-140. doi:https://doi.org/10.1089/jwh.2016.5860

64. Wouk K, Morgan I, Johnson J, et al. A Systematic Review of Patient-, Provider-, and Health System-Level Predictors of Postpartum Health Care Use by People of Color and Low-Incomeand/or Uninsured Populations in the United States. Journal of Women's Health. Published online November 10, 2020. doi:https://doi.org/10.1089/jwh.2020.8738

65. Murray Horwitz M.E., Molina R.L., Snowden J.M. Postpartum care in the United States ' New policies for a new paradigm. New Engl J Med. 2018;379(18):1691-1693. doi:https://doi.org/10.1056/NEJMp1806516

66. Gordon SH, Sommers BD, Wilson IB, Trivedi AN. Effects Of Medicaid Expansion On Postpartum Coverage And Outpatient Utilization. Health Affairs. 2020;39(1):77-84. doi:https://doi.org/10.1377/hlthaff.2019. 00547

67. Celi AC, Seely EW, Wang P, Thomas AM, Wilkins-Haug LE. Caring for Women After Hypertensive Pregnancies and Beyond: Implementation and Integration of a Postpartum Transition Clinic. Matern Child Health J. 2019;23(11): 1459-1466. doi:https://doi.org/10.1007/s10995-01902768-7

68. Bibbo C, Celi A, Thomas AM, Blake-Lamb TL, Wilkins-Haug L. Does the Addition of a Specialized Postpartum Clinic Improve the Care of Women With Preeclampsia? Obstetrics \& Gynecology. 2014;123:39S. doi:https://doi.org/10.1097/01.AOG.0000447316.97709.bd

69. Yee LM, Martinez NG, Nguyen AT, Hajjar N, Chen MJ, Simon MA Using a Patient Navigator to Improve Postpartum Care in an Urban Women's Health Clinic. Obstet Gynecol. 2017;129(5):925-933. doi:https://doi.org/10.1097/AOG.0000000000001977

70. NICKLAS JM, ZERA CA, ENGLAND LJ, et al. A Web-Based Lifestyle Intervention for Women With Recent Gestational Diabetes Mellitus: A Randomized Controlled Trial. Obstet Gynecol. 2014;124(3):563-570. doi:https://doi.org/10.1097/AOG.0000000000000420

71. Rich-Edwards JW, Stuart JJ, Skurnik G, et al. Randomized Trial to Reduce Cardiovascular Risk in Women with Recent Preeclampsia. Journal of Women's Health. 2019;28(11):1493-1504. doi:https://doi. org/10.1089/jwh.2018.7523

72. Sawyer MR, Jaffe EF, Naqvi M, Sarma A, Barth WH, Goldfarb IT. Establishing Better Evidence on Remote Monitoring for Postpartum Hypertension: A Silver Lining of the Coronavirus Pandemic. AJP Rep. 2020;10(3):E315-E318. doi:https://doi.org/10.1055/s-0040-1715169

73. Cusimano MC, Pudwell J, Roddy M, Cho C-KJ, Smith GN. The maternal health clinic: an initiative for cardiovascular risk identification in women with pregnancy-related complications. American Journal of Obstetrics and Gynecology. 2014;210(5):438.e1-438.e9. https://doi.org/ 10.1016/j.ajog.2013.12.001

74. U.S. Department of Health \& Human Services. The Surgeon General's Call to Action to Improve Maternal Health. Published online December 2020. https://www.hhs.gov/sites/default/files/call-to-action-maternal-health.pdf

Publisher's Note: Springer Nature remains neutral with regard to jurisdictional claims in published maps and institutional affiliations. 